\title{
Empowering Asian-American Women through Nostalgia: Power of Female Protagonists in Jasmine, Mrs. Sen's and Seventeen Syllables
}

\author{
Tin Kei Wong
}

\begin{abstract}
Asian-American women have been stereotyped and considered as victims of social injustice in the history of immigration into the United States. The theme of immigrant experience has been recurrent in the writings of female Asian-American writers, reflecting the cultural and female consciousness of Asian-American women. This paper aims to illustrate how three Asian-American women writers, Bharati Mukherjee, Jhumpa Lahiri and Hisaye Yamamoto, empower the Asian-American women under their pens through nostalgia. Three pieces of works of these writers are brought under textual analysis to show how these female Asian-American authors utilize the unique cultural consciousness in the form of nostalgia to entitle power to fictional Asian-American women. This kind of empowerment is read to be a way of the authors to confidently confront their own cultural identity in the multicultural context of the states, hence empowering their own selves.
\end{abstract}

Index Terms-Asian-American short stories, Asian-American women writers, cultural identity, nostalgia.

\section{INTRODUCTION}

Since the first Asian immigrants stepped onto American soil centuries ago, as an ethnic minority, Asian-Americans have been facing social injustice and stereotyping. Asian-American women, in particular, face two major gender stereotypes: they are either aggressive or opportunistic women making use of their female wiles [1], or subservient and exotic sexual beings predated and manipulated by white men [2]. The experience of Asian-American women in the United States in relation to these stereotypes has been a recurrent theme of many writings by female American writers of Asian descent. In these stories, the cultural and female consciousness underlying the texts reflects the writers' identity as female Asian-American writers. Conducting an introductory textual analysis, this paper is to illustrate how three Asian-American women writers, Bharati Mukherjee, Jhumpa Lahiri and Hisaye Yamamoto, empower their Asian-American women protagonists through nostalgia, and to suggest this as a way to confidently confront their own cultural identity.

Despite background differences in terms of ethnicity and age, the Asian-American female protagonists of "Jasmine" in The Middleman and Other Stories (1988) by Bharati Mukherjee [3], "Mrs. Sen's" in Interpreter Of Maladies

Manuscript received June 28, 2014; revised September 3, 2014.

T. K. Wong is with the School of Chinese, The University of Hong Kong, Hong Kong (e-mail: wtkjournals@gmail.com).
(1999) by Jhumpa Lahiri [4] and "Seventeen Syllables" in Seventeen Syllables and Other Stories (2001) by Hisaye Yamamoto [5] seem to have one characteristic in commonthey possess the power as free-willed individuals, who insist on certain aims of life in spite of challenges caused by their gender and ethnicity. Interestingly, all three authors have adopted a similar way to empower the Asian-American women under their pens, which is to make use of objects in relation to nostalgia for their home countries.

\section{Textual Analysis}

\section{A. Jasmine: A Girl Grabbing Banknotes to Secure Herself in Exploitation}

Bharati Mukherjee's short story "Jasmine" narrates how an ambitious 17-year-old Hindu girl Jasmine immigrates illegally to Detroit, the United States, from her home in Trinidad in hope of a brighter future. During her immigration journey, she is exploited by her own father and a white man. Yet, the story entitles her a strong character and a determined will to strive in the American city.

Dr. Vassanji, Jasmine's father, exploits his own daughter by treating her as a tradable object. He encourages Jasmine to leave Trinidad for the United States as he keeps saying that "Girl, opportunity comes only once" [3]. He even assists the illegal immigration by paying the personnel who help Jasmine enter America three thousand back in Trinidad [3]. The line, "they should throw in a good-earning husband for that kind of money," shows Dr. Vassanji's expectation of a wealthy son-in-law in return of the money he spends. On the other hand, Dr. Vassanji's concerns about Jasmine's safety and hardships she might encounter in Detroit are nowhere to be seen in the text. Jasmine can thus be read to be a tradable product that her father invests in, instead of a daughter that the father is emotionally attached to.

The second man exploiting Jasmine is Bill Moffitts, the husband of the American family Jasmine works for. Shortly after working some time as a domestic helper for the family, Jasmine starts an affair with Bill. This relationship is portrayed to be hegemonic that Jasmine is depicted as a subservient sexual object exploited by Bill, a white man. In a scene when the two of them are about to have sex, Bill utters, "You're a blossom, a flower" and "You feel so good, you smell so good. You're really something, flower of Trinidad." [3]. Describing her as "something" in terms of his senses only, Bill reduces Jasmine from a person to a flower, an object of which the attractive appearance and smell are to please him 
sexually. In addition, the way that Bill explicitly refers Jasmine as "flower of Trinidad" further depersonalizes Jasmine that it reduces her to an exotic object.

Although Jasmine is sexually exploited by Bill, it seems that she finds her way to exploit the white man for her personal pleasure at the same time. From the lines, "she felt so good she was dizzy. She'd never felt this good on the island where men did this all the time, and girls went along with it always for favors" [3], we can tell that while Jasmine is conscious of the fact that American men usually have sex with exotic girls who are positioned to be inferior, she does overtly enjoy the moment when this married man makes love to her without promising her any favors. The earlier part of the story tells that Jasmine has been fond of Bill before they have sex. She thinks of Bill all the time and even feels "sick in a giddy, wonderful way" [3]. The narrative also shows how she wishes to replace Lara to become the female host of the family [3]. Hence, Bill's sexual exploitation seems to have fulfilled Jasmine's private romantic wish paradoxically. From the exploitation, Jasmine has the power to enjoy personal pleasure.

Being treated by her father as an object potentially worth great deals of American dollars, Jasmine is herself very money-conscious. At the beginning of the story, the narrative clearly tells Jasmine's desire for greenbacks that, in her eyes, "real money was worn and green, American dollars" [3]. Her determination for earning American money is reflected from the very act that she is willing to take the risks hiding in an empty mattress box to enter Detroit illegally. While Jasmine shows her craving for greenbacks explicitly, she shows no attempts to pay her father the money she earns. This suggests that Jasmine has the individualistic mindset to work for herself even though she is treated as an investment by her father.

Pretty, young and exotic, Jasmine well acknowledges her glamour and advantages which she is readily willing to utilize in order to achieve her goals in the states. Jasmine's consciousness of her own beauty is shown by her almost arrogant reflection that she feels "very superior" when she sees Mr. and Mrs. Daboo whom she describes as "pumpkin-shaped" [3]. Jasmine is also a quick-witted girl who is intelligent enough to please others. After the job interview, Bill tells stories about his camping experience which Jasmine does not feel interested in, but she pretends to be attracted to those activities so as to please him [3]. In a conversation talking about her home country with Lara, the female host of the family, Jasmine is sharp enough to beautify the shabby Port-of-Spain as a romantic island to fascinate the listener. Lara is impressed with Jasmine's narrating ability that she acclaims, "It wouldn't surprise me one bit if you were a writer, Jasmine" [3].

To read the story as a whole, the main storyline depicts how a Trinidad girl who enters the United States illegally for a bright husband eventually ends up having an affair with a married man she works for. In conventional storytelling, Jasmine is a tragic character that is being financially exploited by her father for her monetary potential and sexually exploited by an American white man for her exotic sexuality. However, the writer has entitled a strong personality for Jasmine that she obviously knows her identity and position in the states, making her a strong-willed girl persistent in her goals without asking for any sympathy. Jasmine's determination, as her power, actually stems from banknotes, the object reminding her of her home and identity as an individual. Before immigrating illegally to the states, Jasmine's job is to count bills in a bank in Trinidad. The green American banknotes, besides being the subject matter which Jasmine is in pursuit of, can then be read as something in this foreign place that reminds Jasmine of her job in Trinidad, bringing back a sense of security and cultural identity. Driven by the American banknotes, Jasmine's power as a free-willed individual is vigorous throughout her story of being exploited in the states.

\section{B. Mrs. Sen: A Woman Constructing Herself by Food}

"Mrs. Sen's" is a short story written by Jhumpa Lahiri, narrating how an Indian immigrant wife, Mrs. Sen, who moves to America with his professor husband, refuses to assimilate to American society. Mrs. Sen rejects to feed Elliot, an 11-year-old American boy whom she babysits, with American food. Instead, she insists on preparing cuisines from her culture using the cooking utensils she brings from India. One day, urging to buy whole fish from a seafood market, Mrs. Sen attempts to drive on her own with Elliot but ends up in a car crash. No one gets hurt in the accident, but Mrs. Sen stops preparing food from then and the story ends.

The power that the female protagonist, Mrs. Sen, possesses is the ability to construct her self-identity by means of food. Initially, by advertising herself as "Professor's wife" [4], when she looks for baby-sitting jobs, Mrs. Sen seems to affiliate herself as an auxiliary part of her husband rather than an individual job-seeker. This point is even clearer when she says "Mr. Sen teaches Mathematics at the university" [4], as an introduction of herself to Elliot's mother. So rather than having a self-defined identity, she defines herself by her husband's identity and employment [6] and hence objectifies herself in the first place. However, soon after securing the job of baby-sitting Elliot, Mrs. Sen is able to affiliate herself to an individual when she performs specific acts within her knowledge and expertise, which are taking care of children and preparing food [6]. As the story unfolds, the narrative starts to focus on the interesting depiction of Mrs. Sen's preparation of Indian cuisines at home. The writer places much emphasis on the list of ingredients and the process of how Mrs. Sen uses her blade to chop them [4]. These depictions serve as the pre-texts of Mrs. Sen's monologues, as she only tells Eliot stories of her past life in India and how she feels in America while she is using the blade she brings from home:

She had brought the blade from India, where apparently there was at least one in every household. "Whenever there is a wedding in the family," she told Eliot one day, "or a large celebration of any kind, my mother sends out word in the evening for all neighborhood women to bring blades just like this one, and then they sit in an enormous circle on the roof of our building, laughing and gossiping and slicing fifty kilos of vegetables through the night." Her profile hovered protectively over her work, a confetti of cucumber, eggplant, and onion skins heaped around her. "It is impossible to fall asleep those nights, listening to their chatter." She paused to 
look at a pine tree framed by the living room window. "Here, in this place where Mr. Sen has brought me, I cannot sometimes sleep in so much silence." [4]

The blade obviously recalls Mrs. Sen's comfortable home experience in Calcutta that sharply contrasts with her current isolated life in the states. It holds great significance for Mrs. Sen because it reminds her of her home and hence her cultural identity.

In the story, there are only two things that make Mrs. Sen happy. The first one is receiving letters from her family and the other is getting whole fish from the seaside [4]. This juxtaposition reflects that whole fish allows Mrs. Sen to relate herself to her ethnicity and home. When Mrs. Sen learns that her grandfather passes away, she stops calling the fish store and using the blade [4]. This further shows the significance of food as a connection to her home. Besides, Mrs. Sen shows satisfaction when the fish store owner rings her up to reserve whole fish for her, saying that there is only one Mrs. Sen in the telephone book [4]. Hence, food in the story is also linked with Mrs. Sen's ability to forge a connection with others [6], which is an important quality of being an individual. In this way, fish is a crucial symbol of Mrs. Sen's self-identity as it links to her ethnicity and communication ability as an autonomous person. Moreover, to get to the fish market, Mrs. Sen is willing to step out of home, her zone of safety and comfort, and to perform the fearful task of driving which she has refused to do. This gesture reflects her courage of maintaining her individuality and hence the power of control over her cultural identity.

Readily gaining power from food to construct a self-identity, however, Mrs. Sen loses this power after the car accident. When policemen come to Mrs. Sen to investigate the accident, "Mr. Sen teaches mathematics at the university" [4] is all she says to explain the accident. She does not reveal her desire for fish in relation to her homesickness. Instead, she lets her individuality shrink by defining herself in terms of her husband again, as what she does at the very beginning. Mrs. Sen does not prepare food anymore after the accident. She puts away the blade and throws the ingredients into the garbage bin. Instead of freshly prepared dishes, Mrs. Sen only gives Eliot crackers with peanut butter and popsicles as his meals [4]. As Mrs. Sen is used to attaining emotional satisfaction and self-identification in preparation of cuisines full of freshness and nutrients, the poverty of nourishment in the snacks reflects a poverty of emotional nourishment for Mrs. Sen as well [6]. Mrs. Sen's power is lost along with her home cuisines, which have empowered her through nostalgia to her home country, at the end of story.

\section{Mrs. Hayashi: A Wife Using Haiku to Overpower Her Husband}

Written by Japanese-American writer Hisaye Yamamoto, "Seventeen Syllables" tracks the parallel stories of a second-generation Japanese-American girl Rosie and her first-generation mother Mrs. Hayashi. Working on farms with her husband for a living, Mrs. Hayashi has a strong interest in writing haiku in her spare time. On a harvest day, a haiku editor visits the Hayashi's family and presents the first-prize to Mrs. Hayashi for a poetry contest she enters. Resenting his wife's "luxurious" act of welcoming the editor instead of helping in the harvest, Mr. Hayashi burns the prize. The story ends with Mrs. Hayashi pleading Rosie never to get married.

Mrs. Hayashi has the power of insisting her passion on writing haiku in order to achieve her personal advancement in social status. As seen in the plot, there are consistent power struggles between Mrs. Hayashi and her husband. During the visit to the Hayano family, Mr. Hayashi forces his wife and Rosie to leave while Mrs. Hayashi is discussing a haiku with Mr. Hayano [5]. When the haiku editor comes to their house and gives Mrs. Hayashi the first-prize, Mr. Hayashi does not show any positive reactions. Rather, he grumbles to Rosie that "your mother's crazy!" [5] On top of this rebuke, he sends Rosie to ask Mrs. Hayashi to harvest in the farms, interrupting the conversation between Mrs. Hayashi and the editor. However, Mrs. Hayashi shows disregard of the harvest by insisting on offering tea to the editor and conducting a long conversation with him. With her personal desire overriding the practical needs for a living, she ignores the down-to-earth reminders of Rosie and her husband. At this point, she overpowers her husband by maintaining her individuality and autonomy.

Therefore, Mr. Hayashi's violent action of burning his wife's prize can be read as a measure of regaining control and power in the family [7] when he notices that his wife has overpowered him, instead of an impetuous action purely out of rage. This extreme act not only reflects Mr. Hayashi's resentment of Mrs. Hayashi artistic success, but it also illustrates how patriarchal repression in an Asian-American family can turn into violence when it confronts the power of female individuality.

Mrs. Hayashi's passion on haiku is probably due to the hope to ascend her social status [7], and hence to construct her own identity. Barely knowing English with limited financial ability, writing and sending haiku poems to literary magazines seems to be Mrs. Hayashi's only choice to expand her possibilities to reach a higher social status. As haiku is a Japanese tradition, it is not surprising that Mrs. Hayashi relies on her cultural expertise to construct an individual identity. Indulging in haiku writing, she places her personal desire at a higher priority than livelihood. From the reaction of her husband, we can learn that Mrs. Hayashi's vigorous power of pursuing the individuality is so overt that it threatens her husband. Pleading Rosie never to get married from a woman's perspective, Mrs. Hayashi illustrates her refusal to be bound in a marriage, revealing her strong will to be an individual who is not attached to a husband.

\section{NOSTALGIA AS EMPOWERMENT OF WOMEN}

In the short stories discussed, all of the three female Asian-American protagonists, who are new immigrants to the United States, are given the power of maintaining their individuality and cultural identity. Jasmine insists on earning American banknotes, which is her initial aim of immigration. Although obviously being exploited by her father and an American man, she finds her way to enjoy personal pleasure and satisfaction in the exploitation, demonstrating total control of her own body and mind. Mrs. Sen successfully re-establishes her ethnic identity and finds recognition of 
being an individual in the process of food preparation, despite the loss of power at the end because of an accident. Mrs. Hayashi's pursuit of personal advancement by writing haiku overpowers her husband, as she sacrifices farm work for artistic satisfaction which is seen as extravagance. These three women demonstrate their power in different ways, but one goal is common: they strive to construct a self-identity in relation to their home cultures.

To empower the female protagonists, the three female Asian-American writers have employed different objects which evoke nostalgia for the women's home countries. The way how these objects relate to the past life or home cultures of the characters empower the women and allow them to construct a self-identity. As all the female protagonists are first-generation immigrants who grow up in their home cultures, it is therefore not difficult to imagine how they gain power to build up an individual identity from the objects related to their home experience.

\section{CONCLUSION}

Being Indian-American and Japanese-American, by writing female protagonists of the same ethnicity as them, Mukherjee, Lahiri and Yamamoto have left traces of their own cultural identities in the texts. As argued by Wendy Ho in the book In Her Mother's House: The Politics of Asian American Mother-Daughter Writing [8], female writers are able to take up the responsibility to construct specific images of Asian-American women as mothers, wives, victims, heroes, etc., to redefine an Asian-American woman in the prevalence of typical stereotypes. Likewise, although the three writers discussed have not created a common image for all the female protagonists, they do commonly entitle the women under their pens the autonomy of being a free-willed individual. With objects evoking nostalgia for home cultures as the source of power, the female writers are likely to project their hope of being a free-willed woman in America with a self-identity clearly defined in relation to their home countries, especially when it comes to stereotypes and identity crises in terms of gender and cultural identification in the multicultural context of the United States.

This short paper only offers an introductory textual analysis of three short stories. The personal backgrounds of the three Asian-American female writers, which are believed to be instrumental to the understanding of their female and cultural consciousness, are not included. Besides, the historical context of the stories is worth more discussion to compare the portrayals of female protagonists in the stories and the female immigrants in reality. Comparing and contrasting the differences and similarities, a more comprehensive picture of how and why Asian-American female writers understand and portray immigrant experience of women can be produced. Hence, a further study should look into the personal backgrounds of these Asian-American women writers and the historical contexts in both fiction and reality.

\section{REFERENCES}

[1] G. Hofstede, "Gender stereotypes and partner preferences of asian women in masculine and feminine cultures," Journal of Cross-Cultural Psychology, vol. 27, no. 5, pp. 533-546, March 1996.

[2] R. Tajima, "Lotus blossoms don't bleed: images of Asian women," in Making Waves: An Anthology of Writings by and About Asian American Women, Ed. Asian Women United of California, Boston: Beacon Press, 1989, pp. 308-317.

[3] B. Mukherjee, Jasmine in the Middleman and Other Stories, New York, USA: Grove Press, 1988, pp. 127-138.

[4] J. Lahiri, "Mrs. Sen's" in Interpreter of Maladies, New York, USA: Houghton Mifflin Company, 1999, pp. 111-135.

[5] H. Yamamoto, "Seventeen syllables" in Seventeen Syllables and Other Stories, New Brunswick, New Jersey: Rutgers University Press, 2001, pp. 8-19.

[6] L. A. Williams, "Foodways and subjectivity in Jhumpa Lahiri's interpreter of maladies," MELUS, vol. 32, no. 4, pp. 69-79, Winter 2007.

[7] M. L. Cheng, "The unrepentant fire: tragic limitations in Hisaye Yamamoto's 'seventeen syllables"” MELUS, vol. 19, no. 4, pp. 91-107, 1994.

[8] W. Ho, in Her Mother's House: The Politics of Asian American Mother-Daughter Writing, California: Alta Mira Press, 1999.

T. K. Wong was born in Hong Kong. She obtained her bachelor of arts degree in translation studies and English studies at the University of Hong Kong in 2011. She received her master of philosophy degree in translation studies at same University in 2014

She is currently a lecturer, demonstrator and research assistant in the School of Chinese, the University of Hong Kong. Her research interests include translation studies, cultural studies, gender studies and women's writing. 